by the leftward bulging of the interatrial septum during RV systole, hence reducing left atrial stroke volume and further LV filling. ${ }^{5}$

The cavobipulmonary shunt diverts between $30 \%$ and $40 \%$ of the systemic venous return from the right ventricle. Its beneficial effects are related to increasing LV filling in the presence of RV dysfunction and decreasing the RV wall stress and work index proportional to the decrease in preload. In the first patient, who was operated on during the acute phase of isolated postinfarction RV failure, the rapid postoperative hemodynamic improvement was due to the increased systemic output, rather than to the improvement of systolic performance of the left ventricle, which played a more important role in the other 2 patients who came to surgical intervention later with significant tricuspid regurgitation. The improvement of their postoperative LVEF was certainly due to the additional beneficial effects of RV decompression, hence normalizing interventricular septal motion, increasing left atrial volume, and subsequently achieving effective volume loading of the left ventricle.

We believe that performing a cavobipulmonary shunt in the setting of either the acute or chronic phase of postinfarction congestive RV failure offers a promising and useful therapeutic option.

\section{References}

1. Kinch JW, Ryan TJ. Right ventricular infarction. $N$ Engl J Med. 1994;330:1211-7.

2. Berger PB, Ruocco NA Jr, Ryan TJ, Jacobs AK, Zaret BL, Wackers FJ, et al. Frequency and significance of right ventricular dysfunction during inferior wall left ventricular myocardial infarction treated with thrombolytic therapy (results from the Thrombolysis In Myocardial Infarction (TIMI) II trial). Am J Cardiol. 1993;71:1148-52.

3. Pfisterer M, Emmenegger H, Soler M, Burkhart F. Prognostic significance of right ventricular ejection fraction for persistent complex ventricular arrhythmias and/or sudden cardiac death after first myocardial infarction: relation to infarct location, size, and left ventricular function. Eur Heart J. 1986;7:289-98.

4. Hurwitz A. Left ventricular function in infants and children with symptomatic Ebstein's anomaly. Am J Cardiol. 1994;73:716-8.

5. Louie EK, Bieniarz T, Moore AM, Levitsky S. Reduced atrial contribution to left ventricular filling in patients with severe tricuspid regurgitation after tricuspid valvulectomy: a Doppler echocardiographic study. J Am Coll Cardiol. 1990;16:1617-24.

\title{
Surgical approach to aortic root lesions in patients with homozygous familial hypercholesterolemia and Takayasu arteritis
}

\author{
Stéphane Aubert, MD, Nicolas Bonnet, MD, Pascal Leprince, MD, Théodoro Barreda, MD, Alain Pavie, MD, and \\ Iradj Gandjbakhch, MD, Paris, France
}

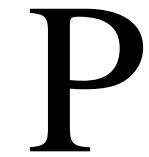
atients with homozygous familial hypercholesterolemia (HFH) and Takayasu arteritis are commonly affected by a severe aortic root calcification associated with coronary ostial stenosis. In these patients a long-term outcome of the coronary artery bypass graft is a permanent preoccupation because of the high risk of progressive arteriosclerosis after surgical repair. We propose an enlargement plasty of the proximal segment of the coronary arteries with a saphenous patch, followed

From the Department of Cardiovascular Surgery, Pitié Salpêtrière Hospital, Paris, France.

Presented at the French Society of Thoracic and Cardio-vascular Surgery's Journées d'automne, December 3, 2004.

Received for publication Dec 31, 2004; revisions received Jan 21, 2005; accepted for publication Feb 8, 2005.

Address for reprints: Stéphane Aubert, MD, Department of Cardiovascular Surgery, Pitié Salpêtrière Hospital, 47-83 boulevard de l'hôpital, 75651 Paris Cedex 13, France (E-mail: stephaneaubert@yahoo.fr).

J Thorac Cardiovasc Surg 2005;130:573-4

$0022-5223 / \$ 30.00$

Copyright $\odot 2005$ by The American Association for Thoracic Surgery

doi:10.1016/j.jtcvs.2005.02.006 by an aortic root replacement with a composite tube graft and coronary reimplantation.

\section{Clinical Summary}

Two patients with HFH and 1 with Takayasu arteritis had severe aortic root calcifications associated with coronary ostial stenosis (1 male and 2 female patients; mean age, $30 \pm 14$ years). Mean aortic gradient ranged from 30 to $70 \mathrm{~mm} \mathrm{Hg}$, with a valvular stenosis in 1 and a supravalvular aortic stenosis in all. All 3 patients had severe ostial coronary stenosis observed by systematic catheterization (occlusion in the case of one right coronary artery). Only 1 patient had angina on effort, with the others being asymptomatic.

At the time of the operation, cardiopulmonary bypass was performed between the right atrium and the aortic arch. Retrograde cold blood was used to achieve cardioplegic arrest. On opening the ascending aorta, severe calcifications of the aortic wall were observed, compromising the lumen. Examination of the aortic root revealed a calcified trileaflet valve in all patients, with significant aortic stenosis in 1 patient. The aorta was divided transversally above the ostia of the coronary arteries. The aortic valve was excised, and the remaining aortic annulus was cleaned of calcium deposits. The coronary arteries were detached, and each was opened longitudinally $1 \mathrm{~cm}$, including an occluded right coronary artery in 1 patient. The coronary artery lumina were enlarged with an oval-shaped patch of saphenous vein (Figure 1). A St Jude 


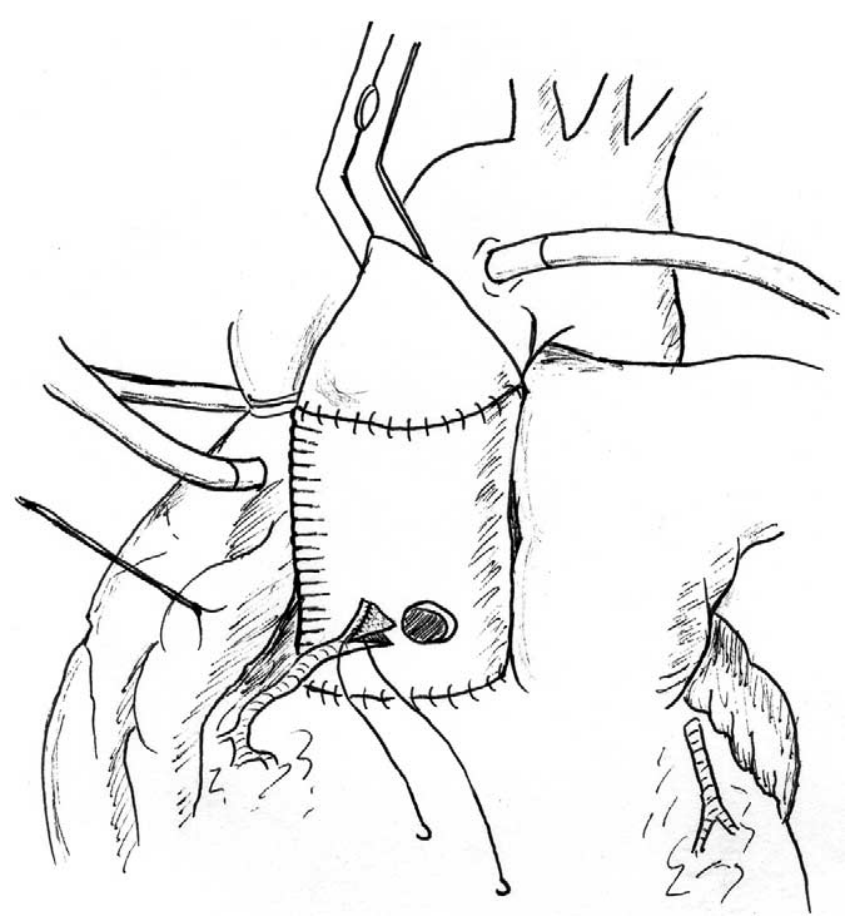

Figure 1. Ascending aorta replaced with a composite tube graft and right coronary ostium lumen augmented with a patch of saphenous vein are shown.

Medical composite tube graft (St Jude Medical, Inc, St Paul, Minn) was implanted with single stitches. The widened coronary arteries were reimplanted laterally into the composite tube graft, similar to the Bentall open technique. The distal anastomosis was fashioned at the base of the brachiocephalic trunk. In 1 patient with severe aortic calcifications extending to the takeoff of the left primitive carotid artery, the distal anastomosis was performed during circulatory arrest and selective anterograde perfusion of the supra-aortic trunks.

All the patients had an uneventful recovery without hemorrhagic or ischemic complications. Postoperative echocardiography, in addition to examination performed 1 and 2 years later, showed a normal motion of the aortic valve and low pressure gradients. Stress test electrocardiography 1 and 2 years later did not reveal residual ischemia. Operative and postoperative parameters are reported in Table 1.

\section{TABLE 1. Operative and postoperative data}

\begin{tabular}{lc}
\hline Data & \\
\hline CPB time (min) & $173 \pm 28$ \\
Crossclamp time (min) & $137 \pm 19$ \\
Hospital stay (d) & $8 \pm 3$ \\
Postoperative LVEF (\%) & $63 \pm 2$ \\
Mean aortic gradient (mm Hg) & $11 \pm 2$ \\
\hline
\end{tabular}

Results are presented as means $\pm \mathrm{SD}$. CPB, Cardiopulmonary bypass; $L V E F$, left ventricular ejection fraction.

\section{Discussion}

Although the pathologic characteristics are different, the lesional consequences observed in Takayasu arteritis and HFH are similar. Each lesion could be treated separately or successively according to its importance: replacement of the aortic root, valvular aortic replacement, ${ }^{1,2}$ or coronary revascularization. ${ }^{1}$ The coronary ostial stenosis is a disease of the aortic wall, with the rest of the coronary arteries being normal in most cases. ${ }^{3}$ This lesion, even if asymptomatic, indicates a revascularization because of the high risk of sudden death. ${ }^{4}$ Percutaneous angioplasty is contraindicated because stenoses are frequently bilateral, calcified, and strictly ostial. Moreover, coronary artery bypass grafting raises the problem of durability. For these reasons, we prefer the surgical plasty of the coronary ostia, just as we are able to treat the aortic root lesions during the same procedure with a Bentall intervention. Our technique is a variant of the Kay-Zubiate procedure. ${ }^{5}$ If the patient is not totally protected from new coronary lesions, including to the repaired ostia, our method reduces the need for coronary grafts, especially arterial grafts. The absence of coronary bypass could simplify reoperations. The supravalvular stenosis can constitute an operative indication because of the importance of its gradient. Because the supravalvular stenosis is located at the sinotubular junction and is associated with a fibrosis retraction of the sinus of Valsalva and with an aortic valvular stenosis, we propose a total replacement of the aortic wall. Thus, the valvular stenosis was not an indication of valvular replacement in 2 patients. Nevertheless, aortic valvular sparing seemed difficult because of the calcifications affecting the cusps and because of the expectation of disease. Recently, $\mathrm{Mu}-$ rashita and colleagues ${ }^{6}$ have reported a technique consisting of an aortic valve replacement associated with a supracommissural aortic tube. In this approach a small segment of aortic root is preserved, and the long-term evolution on restenosis is questionable.

The association of 3 lesions, with at least one justifying a surgical treatment, led us to perform as extensive a combined operation as possible with the salvaging of technical possibilities for a future coronary revascularization. Only long-term follow-up will justify this radical attitude.

\section{References}

1. Yasuda T, Kawasuji M, Sakakibara N, Watanabe Y. Aortic valve replacement for the calcified ascending aorta in homozygous familial hypercholesterolemia. Eur J Cardiothorac Surg. 2000;18:249-50.

2. Forman MB, Kinsley RH, Du Plessis JP, Dansky R, Milner S, Levin SE. Surgical correction of combined supravalvular and valvular aortic stenosis in homozygous familial hypercholesterolaemia. S Afr Med J. 1982;61:579-82.

3. Haitas B, Baker SG, Meyer TE, Joffe BI, Seftel HC. Natural history and cardiac manifestations of homozygous familial hypercholesterolaemia. Q J Med. 1990;76:731-40.

4. Kawaguchi A, Miyatake K, Yutani C, Beppu S, Tsushima M, Yamamura T, et al. Characteristic cardiovascular manifestation in homozygous and heterozygous familial hypercholesterolemia. Am Heart J. 1999;137:410-8.

5. Zubiate P, Kay JH. Surgical treatment of aneurysm of the ascending aorta with aortic insufficiency and marked displacement of the coronary ostia. J Thorac Cardiovasc Surg. 1976;71:415-21.

6. Murashita T, Yoshimoto K, Sugiki H, Yasuda K. Bilateral coronary ostial patch angioplasty with autologous pericardium in Takayasu arteritis: a case requiring replacement of the aortic valve and ascending aorta. Eur J Cardiothorac Surg. 2004;26:866-8. 